\title{
Dietary fibres, fibre analogues, and glucose tolerance: importance of viscosity
}

\author{
DAVID J A JENKINS, THOMAS M S WOLEVER, ANTHONY R LEEDS, MIGUEL A GASSULL, \\ PETER HAISMAN， JANG DILAWARI， DAVID V GOFF，GEOFFREY L METZ，K G M M ALBERTI
}

where the effects on glucose tolerance of several dietary fibres or fibre analogues have been compared with each other. We therefore carried out such a study using a range of substances

\section{Summary and conclusions}

To define the type of dietary fibre or fibre analogue with the greatest potential use in diabetic treatment, groups of four to six volunteers underwent $50-\mathrm{g}$ glucose tolerance tests (GTT) with and without the addition of either guar, pectin, gum tragacanth, methylcellulose, wheat bran, or cholestyramine equivalent to $12 \mathrm{~g}$ fibre. The addition of each substance significantly reduced blood glucose concentration at one or more points during the GTT and generally reduced serum insulin concentrations. The greatest flattening of the glucose response was seen with guar, but this effect was abolished when hydrolysed non-viscous guar was used. The reduction in the mean peak rise in blood glucose concentration for each substance correlated positively with its viscosity $(r=$ $0.926 ; P<0.01)$, as did delay in mouth-to-caecum transit time $(r=0.885 ; P<0.02)$.

Viscous types of dietary fibre are therefore most likely to be therapeutically useful in modifying postprandial hyperglycaemia.

\section{Introduction}

Much recent interest has been shown in treating diabetics with high-fibre ${ }^{12}$ or fibre-supplemented diets $^{345}$ to decrease postprandial hyperglycaemia. The nature of the recommended treatments has been diverse, ranging from raw food (fruit, nuts, and vegetables) to high-carbohydrate, high-fibre diets," both of which have allowed withdrawal or reduction of the insulin dose, and to diets where the only change has been the addition of cellulose to bread. Moreover, wheat $\operatorname{bran}^{6}$ and apples ${ }^{7}$ given unprocessed both flatten glucose tolerance ${ }^{i}$ or the serum insulin response. ${ }^{8}$ Nevertheless, no study has been reported

\section{Department of Regius Professor of Medicine, Radcliffe Infirmary, Oxford \\ DAVID J A JENKINS, DM, DPHIL, research associate \\ University Laboratory of Physiology, Oxford \\ THOMAS M S WOLEVER, BA, research fellow \\ DAVID V GOFF, MIBIOL, senior technician}

MRC Unit and Department of Gastroenterology, Central Middlesex

Hospital, London

ANTHONY R LEEDS, MB, MSC, research fellow

MIGUEL A GASSULL, MD, Wellcome research fellow

JANG DILAWARI, MD, MRCP, senior registrar

GEOFFREY L METZ, MB, FRACP, Stubbins research fellow

Department of Chemical Pathology, Central Middlesex Hospital, London

PETER HAISMAN, MSC, principal biochemist

Department of Pathology and Human Metabolism, Southampton General Hospital, Southampton

K G M M ALBERTI, DPHIL, FRCP, professor of chemical pathology and human metabolism to see what properties and therefore what types of dietary fibre could most usefully be incorporated into the diets of diabetics.

\section{Methods}

Groups of four to six volunteers were drawn from a pool of 11 (10 men, one woman, aged 20-40 years and with body weights of $103 \pm$ $3 \%$ of ideal). ${ }^{9}$ They each took part in two or more experiments, one of which was a control, which were performed in randomised order at least two days apart. The meals were taken over a 10-minute period in the morning after an overnight fast, the basic meal consisting of $50 \mathrm{~g}$ glucose, $25 \mathrm{~g}$ xylose, $15 \mathrm{~g}$ lactulose, and $40 \mathrm{~g}$ PLJ (Pure Lemon Juice, Original sharp, Reckitt and Coleman) in $400 \mathrm{ml}$ of water. To this was added in the test experiments either $14.5 \mathrm{~g}$ of guar (six subjects), tragacanth (six subjects), pectin (six subjects), methylcellulose (five subjects), or $41.5 \mathrm{~g}$ of wheat bran (six subjects) or $12 \mathrm{~g}$ of cholestyramine (four subjects), which, when allowing for hydration, amounted to about $12 \mathrm{~g}$ fibre per meal. Four of the six subjects who originally took guar also took $14.5 \mathrm{~g}$ of partially hydrolysed non-viscous guar with the basic meal six weeks later.

Venous blood samples were taken fasting and 15, 30, 45, 60, 90, and 120 minutes after the start of the meal for analysis of glucose $\mathrm{e}^{10}$ and insulin. ${ }^{11}$ The volunteers emptied their bladders before and two hours after the meal, and an aliquot of the measured volume was taken for xylose estimation. ${ }^{12}$ Also over the first two hours end-expiratory samples were obtained every 15 minutes for analysis of breath hydrogen. ${ }^{13}$ This was used as an index of mouth-to-caecum transit time ${ }^{14}$ and a minimum level of $20 \mathrm{ppm}$ was taken for the first physiologically significant level of hydrogen production. ${ }^{15}$ In the guar experiments urine was collected every two hours for eight hours.

The viscosities used for comparisons here were estimated using Stoke's Law, ${ }^{16}$ which gave the following viscosities in stokes for $1 \%$ solutions at room temperature: guar, $1 \cdot 30 \pm 0.23$; gum tragacanth, $0.52 \pm 0.17$; pectin, $0.21 \pm 0.02$; and methyl cellulose, $0.07 \pm 0.01$. Although they take up water, bran and cholestyramine do not increase viscosity as assessed by this method.

The results were expressed as means $\pm S E$ of mean and the sig nificances of the differences were calculated by Student's $t$ test for paired data.

\section{Results}

Blood glucose-Guar was the only substance that significantly decreased the percentage maximum rise in blood glucose (by $50 \pm 6 \%$; $\mathrm{P}<0.01$ ). All substances, however, produced significantly lower test blood glucose values on one or more occasions during the glucose tolerance test (GTT) (fig 1). During the first hour the area under the blood glucose curve was also significantly reduced by guar $(68 \% ; \mathrm{P}<$ $0.05)$, tragacanth $(34 \% ; \mathrm{P}<0.01)$, and methylcellulose $(29 \% ; \mathrm{P}<$ $0.05)$. There was a positive correlation between viscosity of the individual substances and the mean percentage reduction of the maximum rise in blood glucose concentration $(r=0.926 ; n=6 ; P<0.01)$ and mean percentage reduction of the area under the curve $(r=0.904$ $\mathrm{n}=6 ; \mathrm{P}<0.02$ ). The percentage by which the test value exceeded the control value at 120 minutes was significantly related to viscosity $(\mathrm{r}=0.859 ; \mathrm{n}=6 ; \mathrm{P}<0.05)$.

Serum insulin-The differences in serum insulin response with the different fibres followed the same pattern as the blood glucose concentrations. Guar was the only substance which reduced significantly the percentage maximum rise in serum insulin (by $51 \pm 8 \%$; 


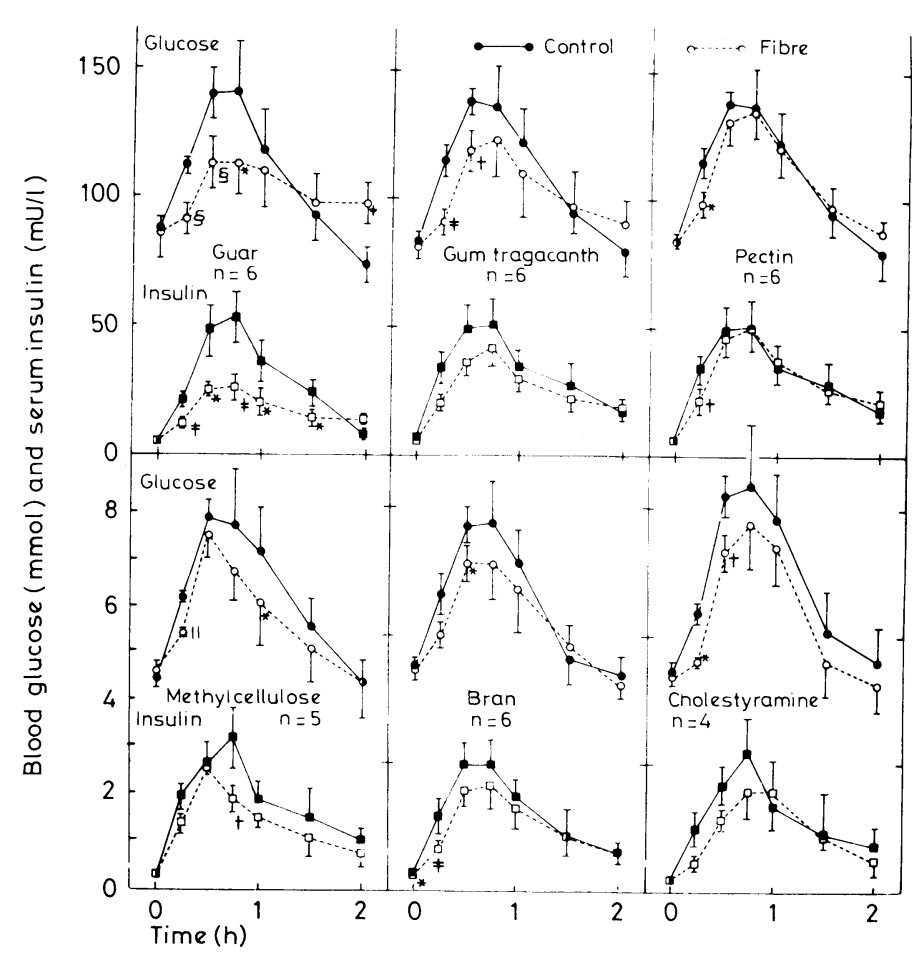

FIG 1-Mean blood glucose and serum insulin concentrations of volunteers after taking control and fibre-containing test meals. Difference from control : ${ }^{*} \mathrm{P}<0.05 ;+\mathrm{P}<0.02 ; \ddagger \mathrm{P}<0.01 ; \$ \mathrm{P}<0.002 ; \mathrm{P}<0.001$.

Conversion: SI to traditional units-Glucose: $1 \mathrm{mmol} / 1 \approx 18 \mathrm{mg} / 100 \mathrm{ml}$.

$\mathrm{n}=5 ; \mathrm{P}<0.01$ ), although in general the test insulin responses were below control values (fig 1). Only in the case of guar, however, was there a significant reduction in the area under the insulin response curve $\left(58^{\circ} ; \mathrm{P}<0.001\right)$. As with glucose, the reduction in the area under the insulin curve correlated with viscosity $(r=0.818 ; n=6$; $\mathrm{P}<0.05)$.

Breath hydrogen transit timeAll substances tested apart from bran and methyl cellulose delayed mouth-to-caecum transit time as judged by the first appearance of breath hydrogen from caecal fermentation of lactulose (fig 2). By taking 20 ppm as the minimum physiologically significant breath hydrogen concentration ${ }^{15}$ the mean control values for the fibres occurred at one and a half to two hours. Guar, tragacanth, pectin, and cholestyramine delayed transit time by $75,30,15$, and 15 minutes respectively. Methylcellulose had no effect, and bran had the opposite effect and reduced transit time by 45 minutes. These figures for mouthto-caecum transit time showed a significant correlation with viscosity $(\mathrm{r}=0.885 ; \mathrm{n}=6 ; \mathrm{P}<0.02)$

Two-hour urinary xylose excretion-A significant decrease in twohour urinary xylose excretion was seen with guar $(P<0.02)$, tragacanth $(P<0.02)$, and bran $(P<0.01)$. The reduction seen with pectin and methylcellulose did not reach significance, and test and control mean values for cholestyramine were almost identical. Collection of two-hourly aliquots continued for eight hours with guar, and the four-to six-hour $(\mathrm{P}<0.02)$ and six- to eight-hour
$(\mathrm{P}<0.002)$ test outputs were significantly higher than the control values. The total eight-hour test and control means were not significantly different $(6 \cdot 1 \pm 0.5 \mathrm{~g}(41 \pm 3.3 \mathrm{mmol})$ and $5 \cdot 7 \pm 0.3 \mathrm{~g}(38 \pm 2 \cdot 0$ $\mathrm{mmol})$ respectively), which indicated delayed absorption with no evidence of malabsorption.

Hydrolysed guar had no effect on the glucose and insulin responses, the two-hour urinary xylose outputs (test $2.9 \pm 3 \mathrm{~g}(19.3 \pm 20.0 \mathrm{mmol})$; control $2 \cdot 3 \pm 2 \mathrm{~g}(15 \cdot 3 \pm 13 \cdot 3 \mathrm{mmol}))$, or mouth-to-caecum transit time.

\section{Discussion}

These results show that gums and natural and synthetic particulate materials that differ widely in physical properties and chemical structure all affect glucose tolerance. Perhaps of greater importance, our results show that viscosity has a considerable effect on absorption and transit time, in that guar, the most viscous substance, was the most effective in decreasing postprandial glucose and insulin concentrations. This was confirmed by the fact that destruction of the viscous character of guar by hydrolysis prevented these actions. With the notable exception of cholestyramine, the two-hour urinary xylose excretion tended to be lower than the control value. As judged by guar this may be an index of slower absorption rather than malabsorption, in that by eight hours the total xylose output after guar was similar to that after the control meal. Among the viscous agents a reduced two-hour urinary xylose output also tended to correspond with a slower mouth-to-caecum transit time-a measurement itself related to viscosity.

The action of viscous agents may be twofold, depending on both delayed gastric emptying and delayed absorption of glucose from the small intestinal lumen. This in turn would result from the greater barrier to diffusion caused by an increased viscosity of the unstirred layer. In addition slower intestinal transit would still allow time for complete absorption. The increase in the blood sugar concentration at two hours and its correction with viscosity may be yet another marker of slower absorption.

No such explanation is applicable to bran or cholestyramine. Barium mixed with wholemeal bread leaves the stomach more

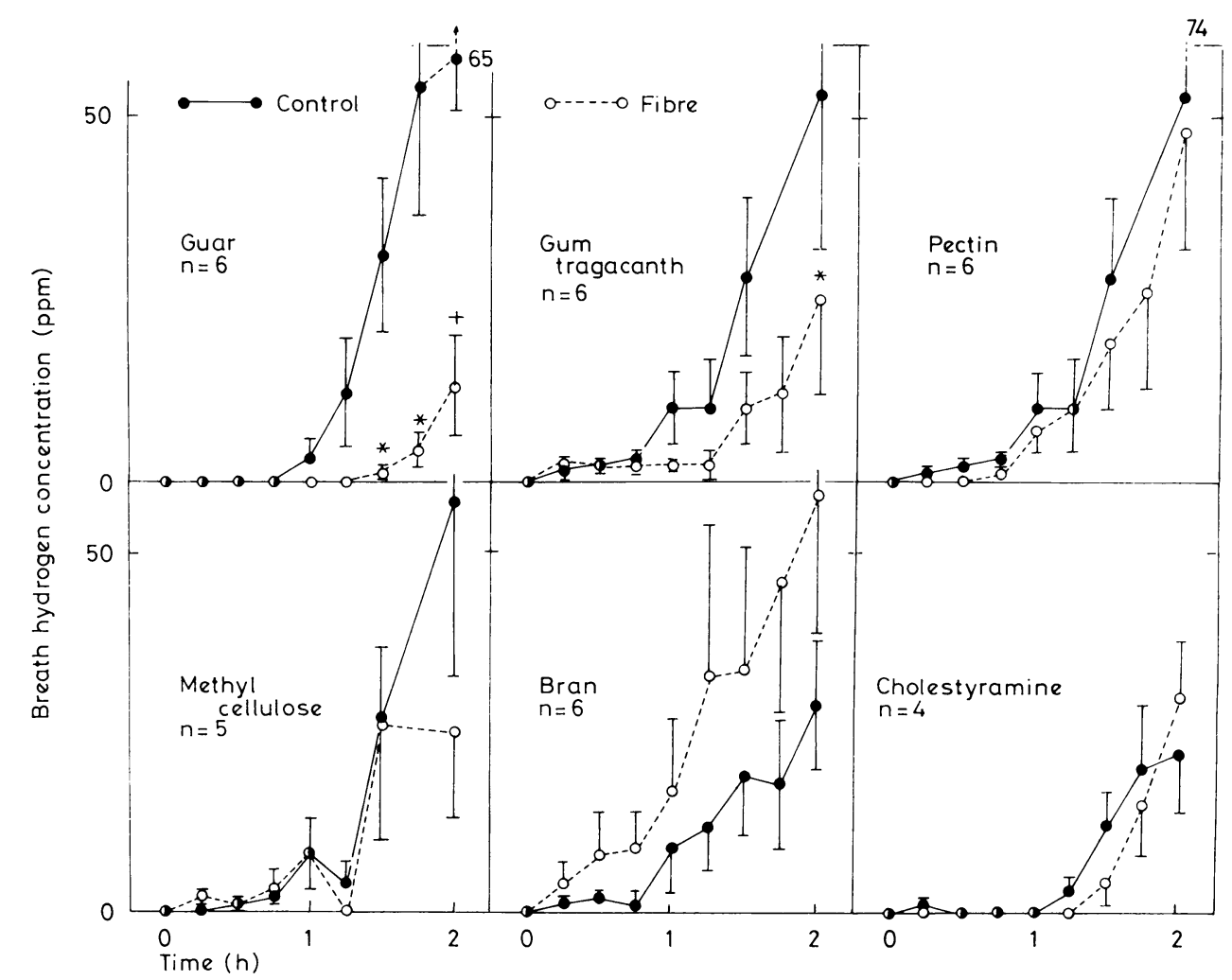

FIG 2-Rise in breath hydrogen as an index of mouth-to-caecum transit time in volunteers after taking control and fibre-containing test meals. ${ }^{*} \mathrm{P}<0 \cdot 05$. $\dagger \mathrm{P}<0.01$. 
rapidly than when mixed with white bread, ${ }^{17}$ and breath hydrogen measurements support a more rapid mouth-to-caecum transit time due to wheat fibre, ${ }^{17}$ although two-hour urinary output of xylose was reduced. Cholestyramine, on the other hand, seemed to have no effect on transit time or xylose absorption and yet still reduced postprandial glycaemia, although only slightly.

Nevertheless, viscosity, through delaying absorption, seems to be one important property of unabsorbable carbohydrate that is useful in reducing the blood glucose concentration. Other

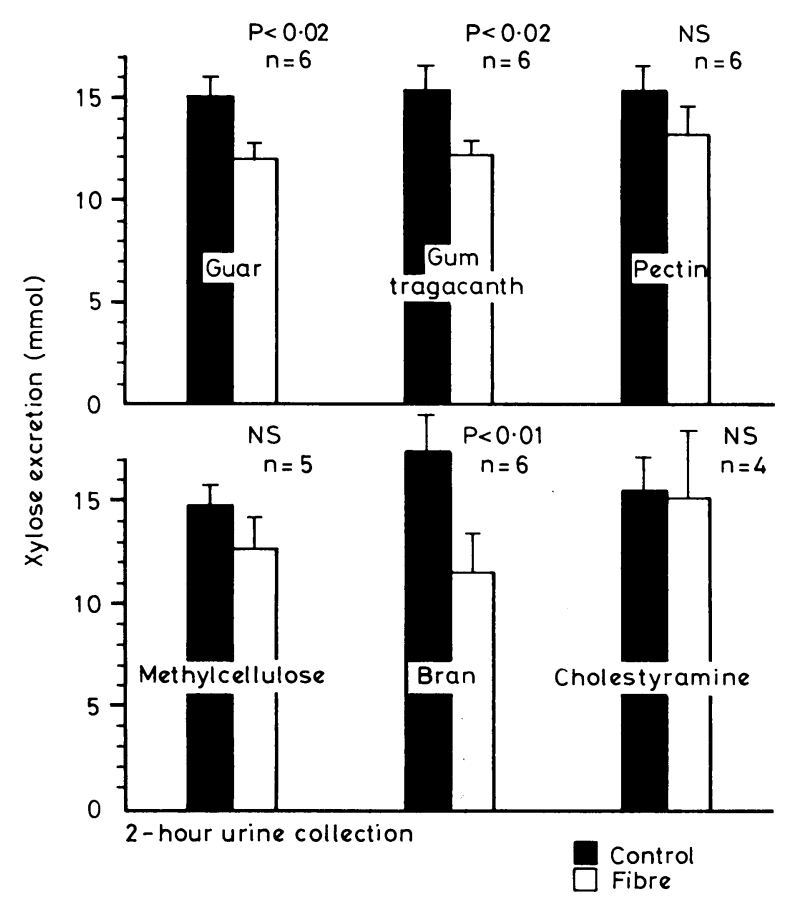

FIG 3-Urinary xylose excretion in volunteers over the first two hours after taking control and fibre-containing test meals. Conversion: SI to traditional units-Xylose : $1 \mathrm{mmol}=0 \cdot 15 \mathrm{~g}$.

factors, such as a changed hormonal background, may play a part, and the gut endocrine system, in particular, might be important. Increased insulin secretion, however, was not the cause of the lower blood glucose concentrations seen.

The effects of fibre, fibre analogues, and fibre-rich foods on postprandial glycaemia have been little tested. Bran has been shown to cause a small reduction in postprandial glycaemia after ingestion of glucose syrup. Reducing the fibre content of apples or potatoes results in higher blood glucose concentrations, ${ }^{7}$ while feeding $60 \mathrm{~g}$ carbohydrate in the form of apples, as opposed to apple juice drunk slowly, resulted in a lower 120-minute blood sugar value and a decreased insulin response. " Unprocessed fruit and raw vegetable diets have been used to replace insulin in diabetic treatment, ${ }^{1}$ as have high-carbohydrate diets rich in wheat fibre."

Our results suggest that wheat and apple fibre, although they have an effect, may not be as effective in reducing postprandial glycaemia as a high-viscosity fibre such as guar. Guar, tragacanth, and pectin are already used as thickeners in the food industry. Guar is a galactomannan, in turn an important dietary fibre of certain legumes, and pectin is a partially methoxylated polymer of galacturonic acid, which is obtained commercially from apples and citrus fruit. Diets of primitive communities are likely to be naturally rich in these types of fibre. Methycellulose is a bulking agent but because of its low viscosity has little effect on glucose tolerance. But viscosity does not explain the effect of cholestyramine in reducing postprandial blood sugar concentration. Guar, ${ }^{1 *}$ pectin,$^{19}$ and cholestyramine all reduce serum cholesterol concentrations, and they might achieve this in part by lowering mean 24-hour insulin concentrations and hence decreasing hepatic cholesterol synthesis.

We conclude that viscosity is the most readily identifiable property of dietary fibre that is related to its action in reducing postprandial glycaemia. Agents which increase viscosity provide one possible approach to the treatment of diabetes.

We thank Sir Francis Avery Jones and Dr E N Rowlands for continuous encouragement; Dr Hal Jabloner of Hercules Powder Co, USA, for much advice; Mr. Harold Godfrey and Mr Bill Horgan of Norgine Ltd for providing both hydrolysed and unhydrolysed guar; and Miss P Bennett for technical help. Pectin was kindly provided by $\mathrm{Mr}$ Tichell of Hercules, UK; H J Heinz supplied gum tragacanth, and $\mathrm{W} B$ Pharmaceuticals provided the methylcellulose.

KGMMA and TMSW were in receipt of grants from the British Diabetic Association. ARL was supported by an MRC training fellowship.

Requests for reprints should be addressed to DJAJ.

\section{References}

${ }^{1}$ Douglas, J M, Annals of Internal Medicine, 1975, 82, 61.

2 Kiehm, T G, Anderson, J W, and Ward K, American fournal of Clinical Nutrition, 1976, 29, 895.

3 Jenkins, D J A, et al, Lancet, 1977, 11, 779.

4 Miranda, P M, and Horwitz, D L, Diabetes, 1977, 26, suppl No 1, p 356

${ }^{5}$ Gillie, O, Sunday Times, 1977, October 23, p 3.

6 Jeffries, D B, Proceedings of the Nutrition Society, 1974, 33, 11A

7 Campbell, G D, in Diabetes, Proceedings of the 7th Congress of the International Diabetes Federation, p 325. Amsterdam, Excerpta Medica, 1971

${ }^{8}$ Haber, G B, et al, Lancet, 1977, 11, 679.

${ }^{9}$ Diem, K, and Lentner, L, editors, Documenta Geigy: Scientific Tables. Basle, Documenta Geigy, 1972.

${ }^{10}$ Werner, W, Key, H G, and Wielinger, H, Fresenius Zeitschrift fur Analytische Chemie, 1970, 252, 244.

11 Soeldner, J S, and Slone, D, Diabetes, 1975, 14, 771.

12 Row, J H, and Rice, E W, Fournal of Biological Chemistry, 1948, 173, 507.

${ }_{13}$ Metz, G, et al, Clinical Science and Molecular Medicine, 1976, 50, 237.

${ }^{14}$ Bond, J H, and Levitt, M D, fournal of Laboratory and Clinical Medicine, $1975,85,546$.

${ }^{15}$ Calloway, D H, Murphy, E L, and Bauer, D, American fournal of Digestive Diseases, $1969, \mathbf{1 4}, 811$.

${ }^{16}$ Nelkon, M, and Ogborn, J M, Advanced Level Practical Physics, 3rd edn, p 272. London, Heinmann Educational Books, 1973.

1: McCance, R A, Prior, K M, and Widdowson, E M, British fournal of Nutrition, 1953, 7, 98.

18 Farenbach, M J, Riccardi, B A, and Grant, W L, Proceedings of the Society of Experimental and Biological Medicine, 1966, 123, 321.

${ }^{19}$ Keys, A, Grande, F, and Anderson, J T, Proceedings of the Society of Experimental and Biological Medicine, 1961, 106, 555.

(Accepted 22 March 1978) 